\title{
Erratum to: Anti-tumor effects of nitrosylcobalamin against spontaneous tumors in dogs
}

\author{
Joseph A. Bauer • Gerald Frye • Anne Bahr • \\ Jennifer Gieg • Peter Brofman
}

Published online: 3 May 2011

(C) Springer Science+Business Media, LLC 2011

\section{Erratum to: Invest New Drugs}

\section{DOI 10.1007/s10637-009-9282-0}

This work was supported in part by Public Health Service grant CA095020 to Cleveland Clinic Foundation from the National Cancer Institute. In addition, Cleveland Clinic Foundation is an owner of a copyright registration for Figure 1, which was used with permission of Cleveland Clinic Foundation (Cleveland, OH).

The online version of the original article can be found at http://dx. doi.org/10.1007/s10637-009-9282-0.

J. A. Bauer $(\bowtie)$

Bauer Research Foundation, Akron Innovation Campus,

411 Wolf Ledges Pkwy, suite 105,

Akron, OH 44311, USA

e-mail: jabauer@bauerresearch.org

G. Frye

PetsDx Veterinary Imaging,

Pittsburgh, PA 15237, USA

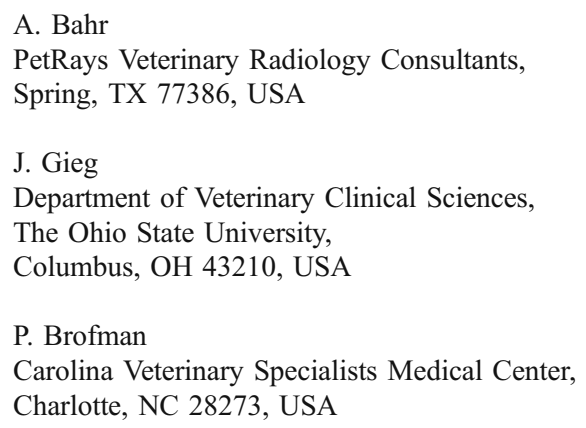

